\title{
Economic evaluation of chemoprevention of breast cancer with tamoxifen and raloxifene among high-risk women in Japan
}

\author{
M Kondo ${ }^{*, 1,2}$, S-L Hoshi' and M Toi ${ }^{3}$ \\ 'Department of Health Care Policy and Management, Graduate School of Comprehensive Human Sciences, University of Tsukuba, I- I-I Tennoudai, \\ Tsukuba, Ibaraki 305-8577, Japan; ${ }^{2}$ Clinical Research Division, Tokyo Metropolitan Cancer and Infectious Disease Centre, Komagome Hospital, 3-18-22 \\ Honkomagome, Bunkyo-ku, Tokyo I I 3-8677, Japan; ${ }^{3}$ Department of Surgery, Graduate School of Medicine, Kyoto University, 54 Kawaracho, Shogoin, \\ Sakyo-ku, Kyoto 606-8507, Japan
}

Raloxifene was approved for chemoprevention against breast cancer among high-risk women in addition to tamoxifen by the US Food and Drug Administration. This study aims to evaluate cost-effectiveness of these agents under Japan's health system. A costeffectiveness analysis with Markov model consisting of eight health states such as healthy, invasive breast cancer, and endometrial cancer is carried out. The model incorporated the findings of National Surgical Adjuvant Breast and Bowel Project P-I and P-2 trial, and key costs obtained from health insurance claim reviews. Favourable results, that is cost saving or cost-effective, are found by both tamoxifen and raloxifene for the introduction of chemoprevention among extremely high-risk women such as having a history of atypical hyperplasia, a history of lobular carcinoma in situ or a 5 -year predicted breast cancer risk of $\geqslant 5.0$ I \% starting at younger age, whereas unfavourable results, that is 'cost more and gain less' or cost-ineffective, are found for women with a 5-year predicted breast cancer risk of $\leqslant 5.00 \%$. Therapeutic policy switch from tamoxifen to raloxifene among postmenopausal women are implied costeffective. Findings suggest that introduction of chemoprevention targeting extremely high-risk women in Japan can be justifiable as an efficient use of finite health-care resources, possibly contributing to cost containment.

British Journal of Cancer (2009) I 00, 28I -290. doi:I0.1038/sj.bjc.6604869 www.bjcancer.com

Published online 13 January 2009

(c) 2009 Cancer Research UK

Keywords: breast cancer; chemoprevention; cost-effectiveness; prophylaxis; raloxifene; tamoxifen

Several clinical trials have demonstrated the effectiveness of prophylactic administration of selective oestrogen receptor modulators (SERMs) such as tamoxifen (Fisher et al, 2005; Cuzick et al, 2007; Powles et al, 2007; Veronesi et al, 2007b) and raloxifene (Cauley et al, 2001; Martino et al, 2004; Vogel et al, 2006) in reducing incidence of breast cancer among women at high risk of developing the disease. Tamoxifen was approved for prophylaxis by the US Food and Drug Administration in 1998, and raloxifene was also approved for postmenopausal women in 2007.

Tamoxifen reduces the risk of breast cancer whereas increasing the risk of adverse events such as endometrial cancer and pulmonary embolism. Raloxifene is a second-generation SERM usually used for osteoporosis treatment, and it reduces the risk of invasive breast cancer with a lower risk of known adverse events associated with SERMs, compared to tamoxifen. This is because raloxifene does not induce the unwanted stimulation of endometrium (Delmas et al, 1997). Therefore, raloxifene is considered to have a better clinical property as prophylactic agent, although it is inferior to tamoxifen in preventing noninvasive breast cancer. More women at high risk of developing breast cancer are expected to take raloxifene as their breast cancer prevention drug in the United States (Bevers, 2007).

*Correspondence: Dr M Kondo; E-mail: mkondo@md.tsukuba.ac.jp Received 2 September 2008; revised 25 November 2008; accepted 5 December 2008; published online 13 January 2009
However, both of these agents have been neither approved nor made available for its use as breast cancer prevention in Japan, although experts have shown their expectations (Iwata and Saeki, 2006). It is said that there are five hurdles to overcome in addressing intervention in the diffusion process of new drug: quality, safety, efficacy, cost-effectiveness, and affordability (Trueman et al, 2001). This paper aims to present evidence to the fourth hurdle, cost-effectiveness of both agents, under Japan's health system. Although cost-effectiveness of prophylactic use of tamoxifen has been reported from the USA (Noe et al, 1999; Grann et al, 2000; Smith and Hillner, 2000; Hershman et al, 2002; Melnikow et al, 2006) and Australia (Eckermann et al, 2003), that of raloxifene has not been published to date except as a part of economic evaluation of osteoporosis management (Armstrong et al, 2001; Kanis et al, 2005). This paper also simulates a therapeutic policy switch from tamoxifen to raloxifene among postmenopausal women to illustrate the relative value of raloxifene. Consequently, it should have implications to the developed countries where chemoprevention with tamoxifen is already in practise.

\section{METHODS}

We conduct a cost-effectiveness analysis with Markov modelling based on the findings of the National Surgical Adjuvant Breast and Bowel Project (NSABP) P-1 trial (Fisher et al, 2005), the NSABP P-2 trial (Vogel et al, 2006), and the literature on costing under 
Japan's health system including sensitivity analyses from societal perspective. Although longer follow-up results for tamoxifen are reported from the first International Breast Cancer Intervention Study (IBIS-I; Cuzick et al, 2007) and the Royal Marsden trial (Powles et al, 2007), NSABP P-1 trial with a shorter follow-up period is chosen as clinical evidence for our modelling to make clear comparisons with NSABP P-2 trial of raloxifene. The longterm outcomes for tamoxifen (Veronesi et al, 2007a) are considered in our sensitivity analyses. We use TreeAge Pro 2008 (TreeAge Software Inc.) for our economic modelling.

\section{High-risk women}

We model high-risk women according to the risk classifications featured in the report of clinical trials: three levels $(\geqslant 1.66,3.01-$ $5.00 \%, \geqslant 5.01 \%)$ of a 5 -year predicted breast cancer risk, with a history of lobular carcinoma in situ (LCIS), and with a history of atypical hyperplasia (AH). A 5-year predicted breast cancer risk of an individual woman used in the trials is based on Gail et al model 2 (Gail and Costantino, 2001), which is validated for white women (Rockhill et al, 2001) and African American women (Gail et al, 2007), to date. We assume the same model is good for Japanese women.

We also model the ages of starting prophylaxis: $35,50,60$ years old for tamoxifen, and 50, 60 years old for raloxifene taking the menopause into account.

\section{Markov model}

We construct a Markov model of courses followed by high-risk women, which is shown in Figure 1. Eight health states are modelled according to clinical events monitored and found significant in P-1 trial and P-2 trial: (1) healthy; (2) invasive breast cancer; (3) noninvasive breast cancer, (4) endometrial cancer; (5) pulmonary embolism; (6) cataract; (7) hip fracture; and (8) dead. Healthy women at high risk of the disease, women with invasive and noninvasive breast cancer are the target health states for chemoprevention. An increase in risk of endometrial cancer, pulmonary embolism, and cataract are known as adverse effects of SERMs, whereas a decrease in risk of hip fracture is known as a beneficial effect. Transitions between health states are indicated with arrows.

The time span of each stage is set at 1 year, since trials report annual incidence rates. Markov process is repeated until death or age 100, whichever comes first, since all events are expected to occur within this time horizon. Women who survive after the age of 100 years are assumed to die regardless of breast cancer development.

\section{Chemoprevention}

Prophylaxis with SERMs is continued for 5 years, or discontinued in case of adverse events, which is similar to the regimen employed in clinical trials.

\section{Comparisons}

We compare outcomes and costs in terms of incremental costeffectiveness ratios (ICERs) between status quo in Japan, without prophylaxis, and hypothetical practise, with prophylaxis, by the agent (tamoxifen and raloxifene), the risk classification, and the age of starting prophylaxis.

$$
\text { ICER }=\frac{\text { Cost }_{\text {with prophylaxis }}-\text { Cost }_{\text {without prophylaxis }}}{\text { Effect }_{\text {with prophylaxis }}-\text { Effect }_{\text {without prophylaxis }}}
$$

We also compare prophylaxis with tamoxifen and prophylaxis with raloxifene to estimate the relative value of raloxifene to tamoxifen, although this does not depict any marginal change in Japan.

\section{Outcome estimation}

Outcomes in terms of life years gained (LYGs) and quality adjusted life years (QALYs) are estimated by assigning transitional probabilities and utility weights to Markov model from the literature.

Transitional probabilities from healthy state to disease states in Markov model are shown in Table 1 according to the findings from the clinical trials. Risk reduction effect of SERMs is assumed to continue during the 5-year course of prophylaxis.

Table 2 summarises other assumptions such as transitional probabilities from disease states to dead state and utility weights used in Markov model. The share of clinical stages of invasive breast cancer at diagnosis are adopted from a nationwide survey on breast cancer screening (Japan Cancer Society, 2007), of which prognosis is calculated from corresponding follow-up cases at Tokyo Metropolitan Cancer and Infectious Disease Centre Komagome Hospital. The prognosis of endometrial cancer is also adopted from a nationwide cancer registry (Japanese Society of Obstetrics and Gynecology, 2000). The prognosis of pulmonary embolism and hip fracture are taken from Sakuma et al (2004); Kitamura et al (1998), respectively. Japanese female population

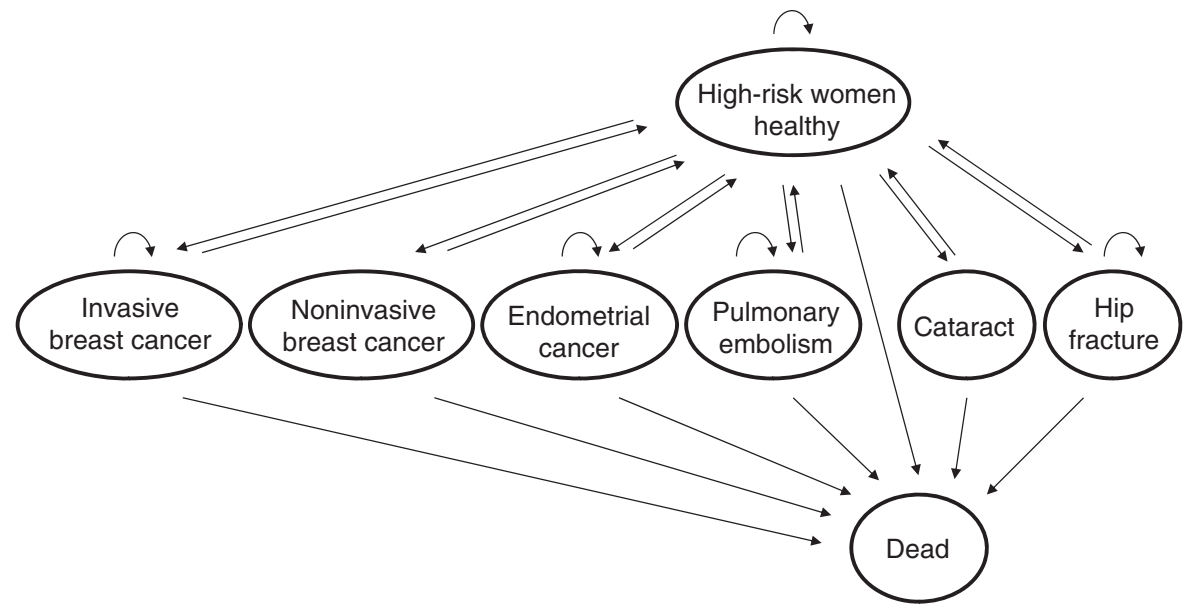

Figure I Markov model. 
Table I Transitional probabilities from healthy state to disease states in Markov model

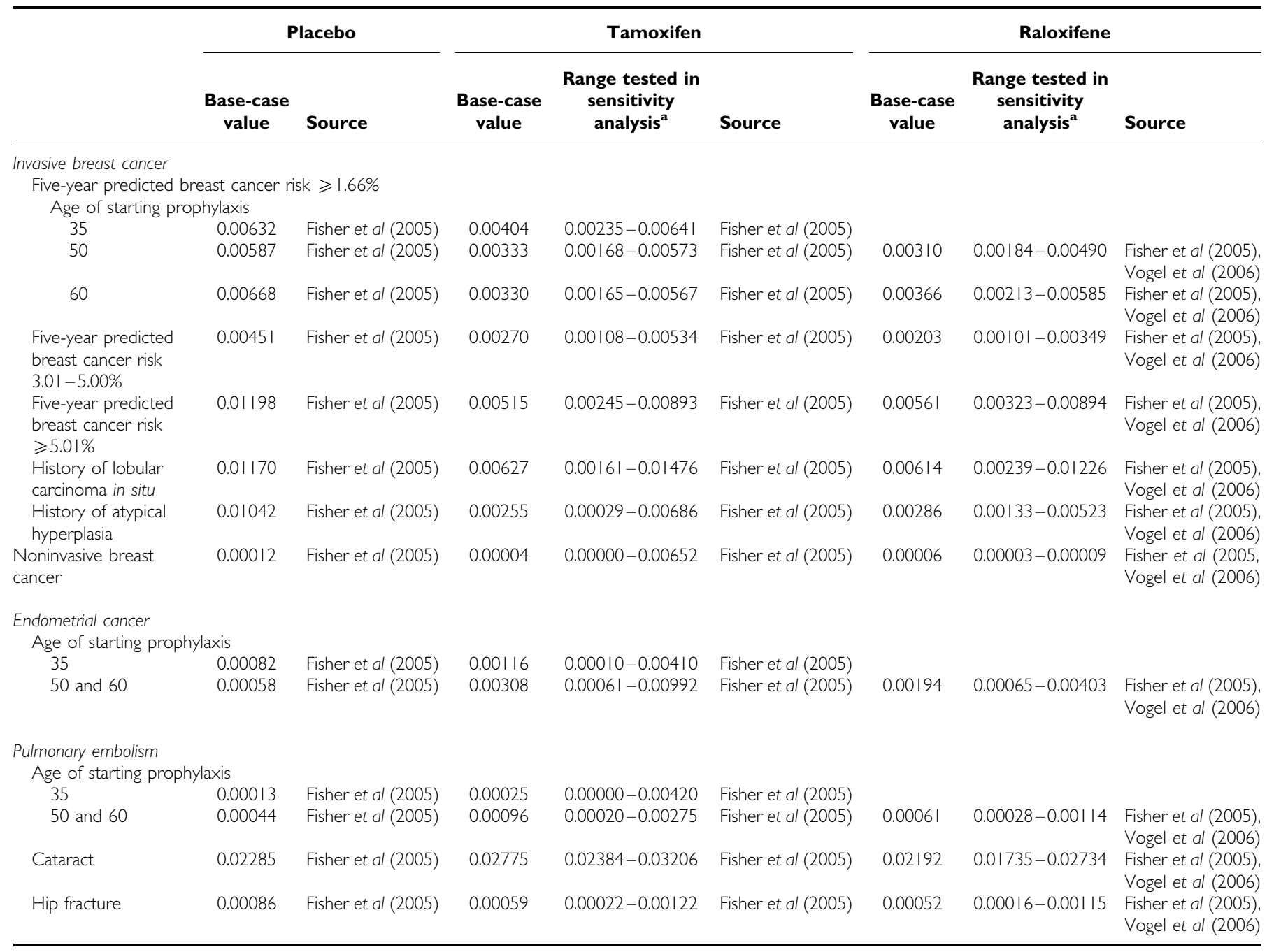

a. 5 times of $95 \%$ confidence interval.

mortality rates from Vital Statistics (Ministry of Health, Labour and Welfare, 2005a) are applied for other transitions to dead state.

It is more preferable to adopt utility weights from a consistent study that assesses our six disease states in Japan, but there is no Japanese utility weight in the literature to date, which may be applied to any health states in our model. To illustrate the typical patient states, we adopt the weights assessed in developed countries considering them as the best available knowledge, and choosing them under the consensus of staff doctors at Tokyo Metropolitan Cancer and Infectious Disease Centre Komagome Hospital (de Koning et al, 1991; Hillner et al, 1993; Smith and Hillner, 1993; Grann et al, 1998; Earle et al, 2000; Armstrong et al, 2001; Chau et al, 2003; Cykert et al, 2004; Naeim and Keeler, 2005; Ruof et al, 2005).

Outcome is discounted at a rate of $3 \%$.

\section{Costing}

From societal perspective, costing should cover the opportunity cost borne by various economic entities in the society. In the context of this study, costs borne by women or third party payers including the government and social insurers are considered, although there is no particular assumption about who bears the cost of chemoprevention. According to the national medical care fee schedule, the amount of direct payments to health-care providers is estimated as cost, whereas costs to sectors other than health and productivity losses are left uncounted.

Health states are identified as cost items in Markov model. Table 3 summarises the cost of each health states. Being in healthy state, women with chemoprevention take $20 \mathrm{mg}$ per day, $¥ 82.6$ ( $£ 0.41 ; £ 1=¥ 200$ ), of tamoxifen, or $60 \mathrm{mg}$ per day, $¥ 148.5$ (£0.74), of raloxifene, prescribed regularly for 5 years, and annual mammography checkup. Women without chemoprevention also undergo annual mammography checkup. Although the state is labelled as 'healthy', it includes all other diseases that are not modelled in Markov model. Annual treatment costs by the age stratum are approximated by annual health-care expenditure per woman adopted from National Health-Care Expenditure (Ministry of Health, Labour and Welfare, 2005b). As it is well known that the cost of health care in the last year of life tends to be large, these are shown separately after an adjustment based on Fukawa (1998).

Table 3 also summarises the treatment cost of invasive breast cancer by the age stratum. In the case of cancer care, the cost in the first year after diagnosis tends to be large as well as in the last year of life, so here again, the costs are shown separately. These figures are obtained from insurance claim reviews at Tokyo Metropolitan Cancer and Infectious Disease Centre Komagome Hospital. As to the cost of the first year, recent breast cancer cases of stage I and 
Table 2 Assumptions used in Markov model

\begin{tabular}{|c|c|c|c|}
\hline & Assumption & $\begin{array}{l}\text { Range tested } \\
\text { in sensitivity } \\
\text { analysis }\end{array}$ & Source \\
\hline \multicolumn{4}{|c|}{ Transitional probabilities from disease states to dead state } \\
\hline \multirow[t]{3}{*}{ Invasive breast cancer } & $\begin{array}{l}0-9 \text { years after diagnosis: prognosis of Japanese breast } \\
\text { cancer patients by the stage } \\
\text { Stage I: } 0.0074,0.0155,0.0113,0.0218,0.0254 \\
0.0248,0.0289,0.0165,0.01632 \\
\text { Stage II: } 0.0054,0.0474,0.0570,0.0334,0.0398 \\
0.0321,0.0275,0.0295,0.04672\end{array}$ & Change by $\pm 50 \%$ & $\begin{array}{l}\text { Calculated from follow-up patients at Komagome } \\
\text { Hospital }\end{array}$ \\
\hline & $\begin{array}{l}\text { (Proportions of stage at diagnosis are assumed } \\
\text { stage I as } 72 \% \text { and stage II as } 28 \% \text { ) }\end{array}$ & Change by $\pm 50 \%$ & Japan Cancer Society (2007) \\
\hline & Thereafter: Japanese female population mortality rates & Change by $\pm 50 \%$ & Ministry of Health, Labour and Welfare (2005a) \\
\hline Noninvasive breast cancer & Japanese female population mortality rates & Change by $\pm 50 \%$ & Ministry of Health, Labour and Welfare (2005a) \\
\hline \multirow[t]{2}{*}{ Endometrial cancer } & $\begin{array}{l}0-4 \text { years after diagnosis: prognosis of Japanese } \\
\text { endometrial cancer patients } 0.0660,0.0546,0.0328 \text {, } \\
0.02813\end{array}$ & Change by $\pm 50 \%$ & Japanese Society of Obstetrics and Gynecology (2000) \\
\hline & Thereafter: Japanese female population mortality rates & Change by $\pm 50 \%$ & Ministry of Health, Labour and Welfare (2005a) \\
\hline \multirow[t]{2}{*}{ Pulmonary embolism } & 0 year after diagnosis: 0.08 & Change by $\pm 50 \%$ & Sakuma et al (2004) \\
\hline & Thereafter: Japanese female population mortality rates & Change by $\pm 50 \%$ & Ministry of Health, Labour and Welfare (2005a) \\
\hline Cataracts & Japanese female population mortality rates & Change by $\pm 50 \%$ & Ministry of Health, Labour and Welfare (2005a) \\
\hline \multirow{2}{*}{ Hip fracture } & $0-1$ years after diagnosis: 0.11 and 0.19 , respectively & Change by $\pm 50 \%$ & Kitamura et al (1998) \\
\hline & Thereafter: Japanese female population mortality rates & Change by $\pm 50 \%$ & Ministry of Health, Labour and Welfare (2005a) \\
\hline \multicolumn{4}{|l|}{ Utility weights } \\
\hline Healthy & 1.00 & Change by $\pm 20 \%$ & \\
\hline $\begin{array}{l}\text { Healthy under } \\
\text { chemoprevention for } 5 \text { years }\end{array}$ & 0.99 & Change by $\pm 20 \%$ & $\begin{array}{l}\text { Smith and Hillner (1993), Hillner et al (1993), } \\
\text { Naeim and Keeler (2005) }\end{array}$ \\
\hline Invasive breast caner & 0 year after diagnosis: 0.87 , thereafter: 0.89 & Change by $\pm 20 \%$ & de Koning et al (1991), Grann et al (1998) \\
\hline Noninvasive breast cancer & 0.98 & Change by $\pm 20 \%$ & Earle et al (2000) \\
\hline Endometrial cancer & 0 year after diagnosis: 0.83, thereafter: 0.88 & Change by $\pm 20 \%$ & Armstrong et al (200I), Cykert et al (2004) \\
\hline Pulmonary embolism & 0.70 & Change by $\pm 20 \%$ & Chau et al (2003) \\
\hline Cataract surgery & 0.96 & Change by $\pm 20 \%$ & Ruof et al (2005) \\
\hline Hip fracture & $0-1$ years after diagnosis: 0.61 and 0.92 , respectively & Change by $\pm 20 \%$ & Armstrong et al (200I) \\
\hline
\end{tabular}

stage II that have undergone initial treatment with a follow-up of 1 year are retrospectively selected so that each age strata has 40 cases. As to the yearly cost of the second year and thereafter, 40 cases for each age strata are randomly selected from follow-up cases initially diagnosed as stage I and stage II. As to the cost of the last year of life, recent 80 fatal cases are retrospectively selected, as the number of these is relatively limited. Insurance claims of these total of 400 cases for 1 year are reviewed to calculate average annual costs by the age strata. Then an adjustment is made to include the cost of prescription to be filled at external pharmacies, such as in the case of adjuvant hormonal therapy, which is based on the consensus among staff doctors.

Costs of disease states are summarised in Table 3 as well. Treatment costs of noninvasive breast cancer, endometrial cancer, cataract, and hip fractures are adopted from a background study for the development of Japanese prospective payment system to health-care providers, diagnosis procedure combination (Matsuda and Ishikawa, 2003), whereas treatment cost of pulmonary embolism is adopted from Fuji et al (2005).

Costs are also discounted at a rate of $3 \%$.

\section{Sensitivity analyses}

To deal with the uncertainty of probabilities, utility weights, and costs used in our economic model, one-way sensitivity analyses are performed. Transitional probabilities from healthy state to disease states shown in Table 1 are varied in 1.5 times of $95 \%$ confidence intervals (CI) reported from the clinical trials. $95 \% \mathrm{CI}$ is often used for similar exercises of sensitivity analyses, but we set wider range for the applicability of the clinical trial data to Japanese women. The other probabilities shown in Table 2 are changed by $\pm 50 \%$. Utility weights are changed by $\pm 20 \%$, and we think this could cover the difference between the utility weights of Japanese women and those of the other developed nations. Costs shown in Table 3 are changed by $\pm 50 \%$. Discount rate is also changed from 0 to $6 \%$.

Acknowledging the long-term outcomes for tamoxifen in the IBIS-I trial (Cuzick et al, 2007) and the Royal Marsden trial (Powles et al, 2007), risk reduction effect of tamoxifen is prolonged from 5 to 10 and 15 years without any risk increase of adverse events after the completion of prophylaxis.

\section{RESULTS}

\section{Outcomes}

Table 4 shows the results of cost-effectiveness analysis comparing prophylaxis with no prophylaxis.

In the comparison between prophylaxis with tamoxifen vs no prophylaxis, most outcomes in terms of LYGs are increased by chemoprevention except for women with a 5-year predicted breast cancer risk of $\geqslant 1.66 \%$ starting at age 50 , and women with a 5-year predicted breast cancer risk of $3.01-5.00 \%$ starting at age 50 and 60. Outcomes in terms of QALYs are also increased except for women with a 5-year predicted breast cancer risk of $\geqslant 1.66 \%$ starting at age 50 and 60 , women with a 5 -year predicted breast cancer risk of $3.01-5.00 \%$, and women with a history of LCIS starting at age 60. The largest outcome gain in terms of QALYs, 0.105 , is estimated among women with a history of AH starting at age 35 .

Between prophylaxis with raloxifene vs no prophylaxis, all outcomes in terms of LYGs are increased by chemoprevention. Outcomes in terms of QALYs are increased except for women with a 5 -year predicted breast cancer risk of $\geqslant 1.66 \%$, and women with 
Table 3 Costs $(¥)$

\begin{tabular}{|c|c|c|c|c|c|c|}
\hline & \multicolumn{3}{|c|}{ Healthy } & \multicolumn{3}{|c|}{ Breast cancer } \\
\hline & $\begin{array}{c}\text { Base-case } \\
\text { value }\end{array}$ & $\begin{array}{c}\text { Range tested in } \\
\text { sensitivity } \\
\text { analysis }\end{array}$ & Source & $\begin{array}{c}\text { Base-case } \\
\text { value }\end{array}$ & $\begin{array}{l}\text { Range tested } \\
\text { in sensitivity } \\
\text { analysis }\end{array}$ & Source \\
\hline \multicolumn{7}{|l|}{ Chemoprevention } \\
\hline Tamoxifen & $30 \mid 49$ & Change by $\pm 50 \%$ & Drug price list, etc & & & \\
\hline Raloxifene & 54203 & Change by $\pm 50 \%$ & & & & \\
\hline $\begin{array}{l}\text { Prescription+annual } \\
\text { mammography }\end{array}$ & 44980 & Change by $\pm 50 \%$ & & & & \\
\hline Annual mammography & 15520 & Change by $\pm 50 \%$ & & & & \\
\hline \multicolumn{7}{|l|}{ Ages $35-49$} \\
\hline First year after diagnosis & & & & 1978064 & Change by $\pm 50 \%$ & \\
\hline Yearly cost & & & & 383743 & Change by $\pm 50 \%$ & \\
\hline Ages 35-39 & 81937 & Change by $\pm 50 \%$ & & & & \\
\hline Ages $40-44$ & 94529 & Change by $\pm 50 \%$ & $\begin{array}{c}\text { Ministry of Health, } \\
\text { Labour and Welfare } \\
\text { (2005b), Fukawa } \\
\text { (1998) }\end{array}$ & & & $\begin{array}{l}\text { Insurance } \\
\text { claim } \\
\text { review }\end{array}$ \\
\hline Ages $45-49$ & 110604 & Change by $\pm 50 \%$ & & & & \\
\hline Terminal care cost, last year of life & & & & 5495224 & Change by $\pm 50 \%$ & \\
\hline Ages $35-39$ & 352331 & Change by $\pm 50 \%$ & & & & \\
\hline Ages $40-44$ & 406474 & Change by $\pm 50 \%$ & & & & \\
\hline Ages $45-49$ & 475599 & Change by $\pm 50 \%$ & & & Change by $\pm 50 \%$ & \\
\hline \multicolumn{7}{|l|}{ Ages $50-64$} \\
\hline First year after diagnosis & & & & 2211083 & Change by $\pm 50 \%$ & \\
\hline Yearly cost & & & & 542857 & Change by $\pm 50 \%$ & \\
\hline Ages 50-54 & 151625 & Change by $\pm 50 \%$ & $\begin{array}{c}\text { Ministry of Health, } \\
\text { Labour and Welfare } \\
\text { (2005b), Fukawa } \\
\text { (1998) }\end{array}$ & & & $\begin{array}{l}\text { Insurance } \\
\text { claim } \\
\text { review }\end{array}$ \\
\hline Ages 55-59 & 195085 & Change by $\pm 50 \%$ & & & & \\
\hline Ages $60-64$ & 258723 & Change by $\pm 50 \%$ & & & & \\
\hline Terminal care cost, last year of life & & & & 4106271 & Change by $\pm 50 \%$ & \\
\hline Ages $50-54$ & 651986 & Change by $\pm 50 \%$ & & & & \\
\hline Ages 55-59 & 838866 & Change by $\pm 50 \%$ & & & & \\
\hline Ages 60-64 & 1112510 & Change by $\pm 50 \%$ & & & & \\
\hline \multicolumn{7}{|l|}{ Ages $65-79$} \\
\hline First year after diagnosis & & & & 1530259 & Change by $\pm 50 \%$ & \\
\hline Yearly cost & & & & $44 \mid 458$ & Change by $\pm 50 \%$ & \\
\hline Ages 65-69 & 324347 & Change by $\pm 50 \%$ & & & & \\
\hline Ages $70-74$ & 460617 & Change by $\pm 50 \%$ & $\begin{array}{c}\text { Ministry of Health, } \\
\text { Labour and Welfare } \\
\text { (2005b), Fukawa } \\
\text { (1998) }\end{array}$ & & & $\begin{array}{l}\text { Insurance } \\
\text { claim } \\
\text { review }\end{array}$ \\
\hline Ages $75-79$ & 549284 & Change by $\pm 50 \%$ & & & & \\
\hline Terminal care cost, last year of life & & & & 3252302 & Change by $\pm 50 \%$ & \\
\hline Ages $65-69$ & 1394690 & Change by $\pm 50 \%$ & & & & \\
\hline Ages $70-74$ & 1980653 & Change by $\pm 50 \%$ & & & & \\
\hline Ages $75-79$ & 2361923 & Change by $\pm 50 \%$ & & & & \\
\hline \multicolumn{7}{|l|}{ Ages $80+$} \\
\hline First year after diagnosis & & & $\begin{array}{c}\text { Ministry of Health, } \\
\text { Labour and Welfare } \\
\text { (2005b), Fukawa } \\
\text { (1998) }\end{array}$ & $961 \mid 81$ & Change by $\pm 50 \%$ & $\begin{array}{l}\text { Insurance } \\
\text { claim } \\
\text { review }\end{array}$ \\
\hline Yearly cost & & & & $185|5|$ & Change by $\pm 50 \%$ & \\
\hline Ages 80-84 & 576290 & Change by $\pm 50 \%$ & & & & \\
\hline Ages $85-89$ & 647941 & Change by $\pm 50 \%$ & & & & \\
\hline Ages 90-94 & 557429 & Change by $\pm 50 \%$ & & & & \\
\hline Ages $95-100$ & 465059 & Change by $\pm 50 \%$ & & & & \\
\hline Terminal care cost, last year of life & & & & 427042 & Change by $\pm 50 \%$ & \\
\hline Ages 80-84 & 2478049 & Change by $\pm 50 \%$ & & & & \\
\hline Ages $85-89$ & $2786 \mid 47$ & Change by $\pm 50 \%$ & & & & \\
\hline Ages 90-94 & 2396943 & Change by $\pm 50 \%$ & & & & \\
\hline Ages $95-100$ & 1999754 & Change by $\pm 50 \%$ & & & & \\
\hline
\end{tabular}


Table 3 (Continued)

\begin{tabular}{|c|c|c|c|}
\hline & \multicolumn{3}{|c|}{ Diseases } \\
\hline & Base-case value & $\begin{array}{l}\text { Range tested in } \\
\text { sensitivity analysis }\end{array}$ & Source \\
\hline $\begin{array}{l}\text { Noninvasive breast cancer surgery, etc } \\
\text { (DPC0900103x020xxx+ } \\
\text { reimbursements by FFS) }\end{array}$ & 847928 & Change by $\pm 50 \%$ & $\begin{array}{l}\text { Matsuda and Ishikawa } \\
\text { (2003) }\end{array}$ \\
\hline \multicolumn{4}{|l|}{ Endometrial cancer } \\
\hline $\begin{array}{l}\text { Total hysterectomy, etc } \\
\text { (DPC I } 200203 \times 01 \times 0 \times \times+ \\
\text { reimbursements by FFS) }\end{array}$ & | 183839 & Change by $\pm 50 \%$ & $\begin{array}{l}\text { Matsuda and Ishikawa } \\
\text { (2003) }\end{array}$ \\
\hline \multicolumn{4}{|l|}{ Pulmonary embolism } \\
\hline $\begin{array}{l}\text { Total } \\
\text { (Diagnosis) } \\
\text { (Treatment) }\end{array}$ & $\begin{array}{r}469890 \\
(52350) \\
(417540)\end{array}$ & Change by $\pm 50 \%$ & Fuji et al (2005) \\
\hline \multicolumn{4}{|l|}{ Cataract } \\
\hline $\begin{array}{l}\text { Surgery, etc (DPC } 0201103 \times 01 \times \\
000 \text { +reimbursements by FFS) }\end{array}$ & 309120 & Change by $\pm 50 \%$ & $\begin{array}{l}\text { Matsuda and Ishikawa } \\
\text { (2003) }\end{array}$ \\
\hline \multicolumn{4}{|l|}{ Hip fracture } \\
\hline $\begin{array}{l}\text { Surgery, etc (DPC } \\
1608003 \times 02 \times \times 0 \times+ \\
\text { reimbursements by FFS) }\end{array}$ & 1553195 & Change by $\pm 50 \%$ & $\begin{array}{l}\text { Matsuda and Ishikawa } \\
\text { (2003) }\end{array}$ \\
\hline
\end{tabular}

DPC: diagnosis procedure combination; FFS: fee for service.

a 5-year predicted breast cancer risk of 3.01-5.00\%. The largest outcome gain in terms of QALYs, 0.058 , is estimated among women with a history of $\mathrm{AH}$ starting at age 50 .

Table 5 shows the results of cost-effectiveness analysis of therapeutic policy switch from tamoxifen to raloxifene.

Raloxifene is consistently superior to tamoxifen across presented risk classifications and starting ages of prophylaxis.

\section{Costs}

In the comparison between prophylaxis with tamoxifen $v s$ no prophylaxis (Table 4), cost savings are estimated in higher risk classifications, among women with a history of LCIS or AH, starting at younger age. The largest saving, $¥ 367901$ ( $£ 1840$ ), is estimated among women with a history of AH starting at age 35 .

Between prophylaxis with raloxifene $v s$ no prophylaxis, prophylaxes are found more costly. A cost saving of $¥ 10387$ (£52) is estimated among women with a history of AH starting at age 50 .

When considering the therapeutic policy switch (Table 5), the use of raloxifene is consistently more costly than tamoxifen, as anticipated by the difference in price of agents.

\section{Cost-effectiveness}

There is a suggested criterion for cost-effectiveness in Japan (Ohkusa, 2003) to be $¥ 6000000$ ( $£ 30000$ ) for one QALY gain, and both Tables 4 and 5 report judgements with this criterion.

In the comparison between prophylaxis with tamoxifen $v s$ no prophylaxis, favourable results, that is 'cost less and gain more' or cost-effective, are obtained in higher risk classifications starting at younger age. Those are: women with a history of $\mathrm{AH}$ regardless of starting age, women with a history of LCIS starting at age 35 and 50 , and women with a 5-year predicted breast cancer risk of $\geqslant 5.01 \%$ starting at age 35 and 50 .

Similar results are found between prophylaxis with raloxifene $v s$ no prophylaxis. Favourable results are: women with a history of
$\mathrm{AH}$ regardless of starting age, women with a history of LCIS starting at age 50 , and women with a 5 -year predicted breast cancer risk of $\geqslant 5.01 \%$ starting at age 50 .

As shown in Table 5, ICERs for the therapeutic policy switch of prophylactic agent from tamoxifen to raloxifene varies from $¥ 1839670$ per QALY ( $£ 9198$ per QALY) to $¥ 6771100$ per QALY ( $₫ 33856$ per QALY). The larger ICER is yet still close to the suggested criterion of $¥ 6000000$ per QALY ( $£ 30000$ per QALY).

\section{Stability of cost-effectiveness}

One-way sensitivity analyses produce similar results across the agents, the risk classifications and the ages of starting prophylaxis. Therefore, we draw a cost-effectiveness plane to show the comparison between prophylaxis with raloxifene $v s$ no prophylaxis among three risk classifications as an example: women with a 5 -year predicted breast cancer risk of $\geqslant 5.01 \%$, women with a history of LCIS, and women with a history of $\mathrm{AH}$.

Figure 2 plots three base-case values and 306 results (102 changes of variables $\times$ three different risk classifications). Line OA indicates the threshold of favourable ICER compared to the suggested criterion of $¥ 6000000$ ( $£ 30000$ ) for one QALY gain. Most results are plotted close to base-case value, which suggest the stability of our model. Results for women with a history of $\mathrm{AH}$ remain constantly favourable being cost saving or cost-effective by the change of variables except for one plot shown as in area $\mathrm{B}$. However, several results for women with a 5-year predicted breast cancer risk of $\geqslant 5.01 \%$ and for women with a history of LCIS cross the threshold line, the vertical axis or the horizontal axis from the base-case values. Three plots in area B and seven plots in area $C$ indicate that results turn unfavourably, that is cost-ineffective or 'gain less', whereas plots in area D show that results become cost saving.

Our model is most sensitive to the utility weight for healthy state under chemoprevention, of which plots are drawn in area $\mathrm{B}$. Its change to 0.79 turns incremental effectiveness into 
Table 4 Results of cost-effectiveness analysis (I)

\begin{tabular}{|c|c|c|c|c|c|c|c|c|c|c|c|}
\hline \multirow{2}{*}{$\begin{array}{l}\text { No prophylaxis vs } \\
\text { prophylaxis } \\
\text { with tamoxifen }\end{array}$} & \multicolumn{3}{|c|}{ CoCost ( $¥)$} & \multicolumn{3}{|c|}{ Effectiveness (LYGs) } & \multicolumn{3}{|c|}{ Effectiveness (QALYs) } & \multicolumn{2}{|c|}{$\begin{array}{l}\text { Incremental cost- } \\
\text { effectiveness ratio }\end{array}$} \\
\hline & $\begin{array}{c}\text { No } \\
\text { prophylaxis }\end{array}$ & Tamoxifen & Incremental & $\begin{array}{c}\text { No } \\
\text { prophylaxis }\end{array}$ & Tamoxifen & Incremental & $\begin{array}{c}\text { No } \\
\text { prophylaxis }\end{array}$ & Tamoxifen & Incremental & (¥/LYG) & ( $¥ / Q A L Y)$ \\
\hline \multicolumn{12}{|c|}{ Five-year predicted breast cancer risk $\geqslant 1.66 \%$} \\
\hline Starting at age 35 & 13958679 & 13983626 & 24947 & 25.916 & 25.953 & 0.037 & 25.757 & 25.759 & 0.002 & 678210 & 14247447 \\
\hline Starting at age 50 & 17630814 & 17751353 & 120538 & 22.168 & 22.167 & -0.001 & 22.040 & 22.000 & -0.040 & $\begin{array}{l}\text { Cost more, } \\
\text { gain less }\end{array}$ & $\begin{array}{c}\text { Cost more, } \\
\text { gain less }\end{array}$ \\
\hline Starting at age 60 & 20160906 & 20324294 & 163388 & 18.806 & 18.807 & 0.001 & 18.688 & 18.654 & -0.034 & 120849008 & $\begin{array}{l}\text { Cost more, } \\
\text { gain less }\end{array}$ \\
\hline \multicolumn{12}{|c|}{ Five-year predicted breast cancer risk $3.01-5.00 \%$} \\
\hline Starting at age 35 & 13627472 & 13685368 & 57896 & 26.005 & 26.035 & 0.030 & 25.879 & 25.872 & -0.007 & 1946092 & $\begin{array}{c}\text { Cost more, } \\
\text { gain less }\end{array}$ \\
\hline Starting at age 50 & 17579407 & 17732900 & 153493 & 22.195 & 22.185 & -0.010 & 22.088 & 22.037 & -0.051 & $\begin{array}{l}\text { Cost more, } \\
\text { gain less }\end{array}$ & $\begin{array}{c}\text { Cost more, } \\
\text { gain less }\end{array}$ \\
\hline Starting at age 60 & 20251937 & $20444|4|$ & 192203 & 18.808 & 18.797 & -0.011 & 18.718 & 18.666 & -0.052 & $\begin{array}{l}\text { Cost more, } \\
\text { gain less }\end{array}$ & $\begin{array}{c}\text { Cost more, } \\
\text { gain less }\end{array}$ \\
\hline \multicolumn{12}{|c|}{ Five-year predicted breast cancer risk $\geqslant 5.01 \%$} \\
\hline Starting at age 35 & 14956349 & 14667969 & -288380 & 25.651 & 25.755 & 0.105 & 25.396 & 25.480 & 0.084 & $\begin{array}{l}\text { Cost less, } \\
\text { gain more }\end{array}$ & $\begin{array}{l}\text { Cost less, } \\
\text { gain more }\end{array}$ \\
\hline Starting at age 50 & $17867 \mid 46$ & 17800766 & -66379 & 22.049 & 22.096 & 0.047 & 21.832 & 21.854 & 0.022 & $\begin{array}{l}\text { Cost less, } \\
\text { gain more }\end{array}$ & $\begin{array}{l}\text { Cost less, } \\
\text { gain more }\end{array}$ \\
\hline Starting at age 60 & 19958433 & 20058020 & 99857 & 18.797 & 18.825 & 0.028 & 18.614 & 18.618 & 0.004 & 3548049 & 26648821 \\
\hline \multicolumn{12}{|c|}{ History of lobular carcinoma in situ } \\
\hline Starting at age 35 & 14908314 & 14717649 & -190665 & 25.663 & 25.747 & 0.083 & 25.414 & 25.472 & 0.058 & $\begin{array}{l}\text { Cost less, } \\
\text { gain more }\end{array}$ & $\begin{array}{l}\text { Cost less, } \\
\text { gain more }\end{array}$ \\
\hline Starting at age 50 & $17856 \mid 58$ & 17850722 & -5386 & 22.054 & 22.085 & 0.031 & 21.841 & 21.843 & 0.002 & $\begin{array}{l}\text { Cost less, } \\
\text { gain more }\end{array}$ & $\begin{array}{l}\text { Cost less, } \\
\text { gain more }\end{array}$ \\
\hline Starting at age 60 & 19968466 & 20093211 & 124745 & 18.798 & 18.815 & 0.017 & 18.618 & 18.606 & -0.011 & 7282700 & $\begin{array}{l}\text { Cost more, } \\
\text { gain less }\end{array}$ \\
\hline \multicolumn{12}{|c|}{ History of atypical hyperplasia } \\
\hline Starting at age 35 & 14687003 & 14319102 & -367901 & 25.722 & 25.844 & 0.122 & 25.493 & 25.598 & 0.105 & $\begin{array}{l}\text { Cost less, } \\
\text { gain more }\end{array}$ & $\begin{array}{l}\text { Cost less, } \\
\text { gain more }\end{array}$ \\
\hline Starting at age 50 & 17806095 & 17692020 & -114075 & 22.079 & 22.139 & 0.060 & 21.884 & 21.922 & 0.038 & $\begin{array}{l}\text { Cost less, } \\
\text { gain more }\end{array}$ & $\begin{array}{l}\text { Cost less, } \\
\text { gain more }\end{array}$ \\
\hline Starting at age 60 & 20015243 & 20096731 & 81488 & 18.800 & | 8.837 & 0.037 & 18.635 & $18.65 \mid$ & 0.016 & 2226684 & $5234647^{a}$ \\
\hline
\end{tabular}

\begin{tabular}{|c|c|c|c|c|c|c|c|c|c|c|c|}
\hline $\begin{array}{l}\text { No prophylaxis vs } \\
\text { prophylaxis with } \\
\text { raloxifene }\end{array}$ & $\begin{array}{c}\text { No } \\
\text { prophylaxis }\end{array}$ & Raloxifene & Incremental & $\begin{array}{c}\text { No } \\
\text { prophylaxis }\end{array}$ & Raloxifene & Incremental & $\begin{array}{c}\text { No } \\
\text { prophylaxis }\end{array}$ & Raloxifene & Incremental & (¥/LYG) & (¥/QALY) \\
\hline \multicolumn{12}{|c|}{ Five-year predicted breast cancer risk $\geqslant 1.66 \%$} \\
\hline Starting at age 50 & 17630814 & 17833020 & 202206 & 22.168 & 22.190 & 0.022 & 22.040 & 22.027 & -0.013 & 9256382 & $\begin{array}{c}\text { Cost more, } \\
\text { gain less }\end{array}$ \\
\hline Starting at age 60 & 20160906 & 20427386 & 266480 & 18.806 & 18.822 & 0.016 & 18.688 & 18.670 & -0.018 & 16806286 & $\begin{array}{l}\text { Cost more, } \\
\text { gain less }\end{array}$ \\
\hline \multicolumn{12}{|c|}{ Five-year predicted breast cancer risk $3.01-5.00 \%$} \\
\hline Starting at age 50 & 17579407 & 17794890 & 215482 & 22.195 & 22.214 & 0.019 & 22.088 & 22.071 & -0.017 & 11599422 & $\begin{array}{c}\text { Cost more, } \\
\text { gain less }\end{array}$ \\
\hline Starting at age 60 & 20251937 & 20529452 & 277515 & 18.808 & 18.820 & 0.012 & 18.718 & 18.694 & -0.024 & 23845594 & $\begin{array}{c}\text { Cost more, } \\
\text { gain less }\end{array}$ \\
\hline \multicolumn{12}{|c|}{ Five-year predicted breast cancer risk $\geqslant 5.01 \%$} \\
\hline Starting at age 50 & $17867 \mid 46$ & 17911198 & 44053 & 22.049 & 22.111 & 0.062 & 21.832 & 21.871 & 0.039 & 705126 & $1123880^{\mathrm{a}}$ \\
\hline Starting at age 60 & 19958433 & 20161888 & 203455 & 18.797 & 18.839 & 0.042 & 18.614 & 18.633 & 0.019 & 4848677 & 10664954 \\
\hline \multicolumn{12}{|c|}{ History of lobular carcinoma in situ } \\
\hline Starting at age 50 & 17856158 & 17935697 & 79540 & 22.054 & 22.107 & 0.053 & 21.841 & 21.869 & 0.027 & 1496425 & $2904386^{a}$ \\
\hline Starting at age 60 & 19968466 & 20186549 & 218083 & 18.798 & 18.833 & 0.036 & 18.618 & 18.628 & 0.010 & 6133167 & 21462765 \\
\hline \multicolumn{12}{|c|}{ History of atypical hyperplasia } \\
\hline Starting at age 50 & 17806095 & 17795708 & -10387 & 22.079 & 22.156 & 0.077 & 21.884 & 21.942 & 0.058 & \multirow{2}{*}{$\begin{array}{l}\text { Cost less, } \\
\text { gain more } \\
3527453\end{array}$} & $\begin{array}{l}\text { Cost less, } \\
\text { gain more }\end{array}$ \\
\hline Starting at age 60 & 20015243 & 20198328 & 183085 & 18.800 & 18.852 & 0.052 & 18.635 & 18.668 & 0.033 & & $5570154^{a}$ \\
\hline
\end{tabular}

${ }^{a}$ Cost-effective when compared to a suggested criterion in Japan (Ohkusa, 2003) of $¥ 6000000$ for one QALY gain.

negative. Critical values to change the judgement are 0.98 , which makes the ICERs of women with a 5-year predicted breast cancer risk of $\geqslant 5.01 \%$ and woman with a history of LCIS cost-ineffective, and the value of 0.96 makes women with a history of AH 'gain less'. The model is also sensitive to the discount rate, of which plot is drawn in area C. Its raise of 5.9 and $4.3 \%$ makes the ICERs of women with a 5 -year predicted breast cancer risk of $\geqslant 5.01 \%$ and women with a history of 
Table 5 Results of cost-effectiveness analysis (2)

\begin{tabular}{|c|c|c|c|c|c|c|c|c|c|c|c|}
\hline \multirow[b]{2}{*}{$\begin{array}{l}\text { Prophylaxis with } \\
\text { tamoxifen vs } \\
\text { prophylaxis with } \\
\text { raloxifene }\end{array}$} & \multicolumn{3}{|c|}{ Cost (¥) } & \multicolumn{3}{|c|}{ Effectiveness (LYGs) } & \multicolumn{3}{|c|}{ Effectiveness (QALYs) } & \multicolumn{2}{|c|}{$\begin{array}{c}\text { Incremental } \\
\text { cost-effectiveness } \\
\text { ratio }\end{array}$} \\
\hline & Tamoxifen & Raloxifene & Incremental & Tamoxifen & Raloxifene & Incremental & Tamoxifen & Raloxifene & Incremental & (¥/LYG) & ( $¥ / Q A L Y)$ \\
\hline \multicolumn{12}{|c|}{ Five-year predicted breast cancer risk $\geqslant 1.66 \%$} \\
\hline Starting at age 50 & 17751353 & 17833020 & 81667 & 22.167 & 22.190 & 0.023 & 22.000 & 22.027 & 0.027 & 3501723 & $3035955^{\mathrm{a}}$ \\
\hline Starting at age 60 & 20324294 & 20427386 & 103093 & 18.807 & 18.822 & 0.015 & 18.654 & 18.670 & 0.016 & 7107875 & 6364920 \\
\hline \multicolumn{12}{|c|}{ Five-year predicted breast cancer risk $3.01-5.00 \%$} \\
\hline Starting at age 50 & 17732900 & 17794890 & 61990 & 22.185 & 22.214 & 0.029 & 22.037 & 22.071 & 0.034 & 2163079 & $1839670^{\mathrm{a}}$ \\
\hline Starting at age 60 & $20444|4|$ & 20529452 & 85312 & 18.797 & 18.820 & 0.023 & 18.666 & 18.694 & 0.028 & 3741906 & $3063477^{\mathrm{a}}$ \\
\hline \multicolumn{12}{|c|}{ Five-year predicted breast cancer risk $\geqslant 5.01 \%$} \\
\hline Starting at age 50 & 17800766 & 17911198 & 110432 & 22.096 & 22.111 & 0.015 & 21.854 & 21.871 & 0.017 & 7150490 & 6542190 \\
\hline Starting at age 60 & 20058020 & 20161888 & 103869 & 18.825 & 18.839 & 0.014 & 18.618 & 18.633 & 0.015 & 7476332 & $677 \mid 100$ \\
\hline \multicolumn{12}{|c|}{ History of lobular carcinoma in situ } \\
\hline Starting at age 50 & 17850772 & 17935697 & 84925 & 22.085 & 22.107 & 0.022 & 21.843 & 21.869 & 0.025 & 3846426 & $3359650^{\mathrm{a}}$ \\
\hline Starting at age 60 & 20093211 & 20186549 & 93338 & 18.815 & 18.833 & 0.018 & 18.606 & 18.628 & 0.022 & 5064724 & $4311015^{\mathrm{a}}$ \\
\hline \multicolumn{12}{|c|}{ History of atypical hyperplasia } \\
\hline Starting at age 50 & 17692020 & 17795708 & 103688 & 22.139 & 22.156 & 0.018 & 21.922 & 21.942 & 0.019 & 5922294 & $5320037^{\mathrm{a}}$ \\
\hline Starting at age 60 & 20096731 & 20198328 & 101598 & 18.837 & 18.852 & 0.015 & $|8.65|$ & 18.668 & 0.017 & 6637332 & $5872017^{\mathrm{a}}$ \\
\hline
\end{tabular}

${ }^{a}$ Cost-effective when compared to a suggested criterion in Japan (Ohkusa, 2003) of $¥ 6000000$ for one QALY gain.

$\times$ 5-yearpredicted risk $\geqslant 5.01 \%$

$\Delta$ History of LCIS

O History of $\mathrm{AH}$

- Stands for base-case value
Incremental cost ( $¥)$

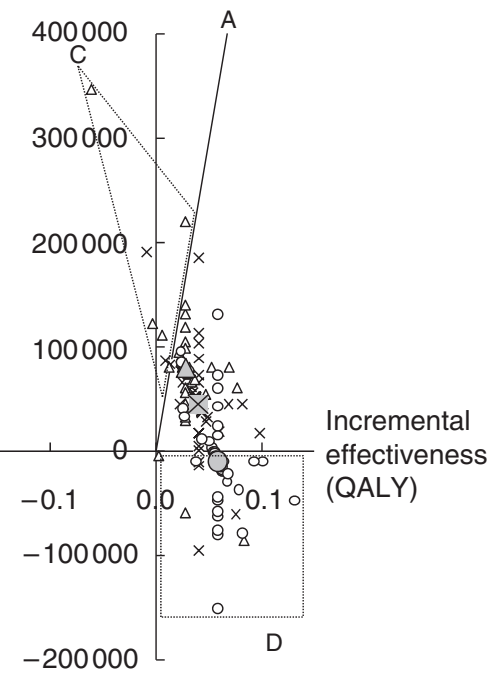

Figure 2 Illustration of key results of sensitivity analyses: prophylaxis with raloxifene vs no prophylaxis starting at age 50.

LCIS cost-ineffective, respectively. The cost of chemoprevention is also influential to the results, of which results are shown in areas $\mathrm{C}$ and D. A price increase of more than $30 \%$ for raloxifene makes the ICER of women with a history of LCIS cost-ineffective, whereas a price decrease of more than 16 or $29 \%$ make the results for women with a 5 -year predicted breast cancer risk of $\geqslant 5.01 \%$ and women with a history of LCIS cost saving, respectively. Changes of the probabilities of transition to invasive breast cancer, endometrial cancer, and hip fracture are also plotted in areas $\mathrm{C}$ and $\mathrm{D}$. Raising the probability of invasive breast cancer beyond 0.00710 and 0.00683 makes the ICERs of women with a 5 -year predicted breast cancer risk of $\geqslant 5.01 \%$ and women with a history of LCIS cost-ineffective, whereas lowering to less than 0.00456 or 0.00436 make the results for women with a 5-year predicted breast cancer risk of $\geqslant 5.01 \%$ and women a history of LCIS cost saving, respectively. Raising the probability of endo- metrial cancer beyond 0.00369 and 0.00271 makes the ICERs of women with a 5 -year predicted breast cancer risk of $\geqslant 5.01 \%$ and women with a history of LCIS cost-ineffective, respectively. Raising probability of hip fracture beyond 0.00098 makes the results for women with a history of LCIS cost saving. The other plots in area C reflect a raise of utility weight for invasive breast cancer after the second year.

Prolonging risk reduction effect of tamoxifen from 5 to 10 and 15 years without any risk increase of adverse events after the completion of prophylaxis brings more favourable results. For example, the effect of 10 years results in 'cost less and gain more' for every risk classification starting at age 35 , whereas the effect of 15 years makes no change in the results of 'cost more and gain less' among women with a 5 -year predicted breast cancer risk of $\geqslant 1.66 \%$ starting at age 50 and 60. 


\section{DISCUSSION}

We conduct a cost-effectiveness analysis of SERMs as prophylactic agents against breast cancer among high-risk women by making comparisons between status quo in Japan, without prophylaxis, and hypothetical practise, with prophylaxis, by the agent (tamoxifen and raloxifene), the risk classification, and the age of starting prophylaxis.

We find that prophylaxis with tamoxifen results in 'cost less and gain more' among extremely high-risk women such as those with a 5 -year predicted breast cancer risk of $\geqslant 5.01 \%$, those with a history of LCIS, and those with a history of AH starting at age 35 and 50. Prophylaxis with raloxifene is also found 'cost less and gain more' for women with a history of $\mathrm{AH}$ starting at age 50 . The younger the age of starting prophylaxis, the more the cost saving and outcome gain. We also find that prophylaxis with tamoxifen for women with a history of $\mathrm{AH}$ starting at age 60 results in favourable ICER compared to the suggested criterion of $¥ 6000000$ ( $£ 30000$ ) for one QALY gain. Prophylaxis with raloxifene is also found cost-effective for women with a 5 -year predicted breast cancer risk of $\geqslant 5.01 \%$ starting at age 50, those with a history of LCIS starting at age 50 and those with a history of $\mathrm{AH}$ starting at age 60 . The younger the age of starting prophylaxis, the more favourable the ICER. Within the same risk classification and starting age, raloxifene tends to gain more and cost more compared to tamoxifen. On the contrary, we also find that prophylaxes with tamoxifen or raloxifene for women with a 5-year predicted breast cancer risk of $\leqslant 5.00 \%$ tend to result in 'cost more and gain less'.

These findings are similar to the previous economic evaluations of chemoprevention of breast cancer with tamoxifen including analyses of risk level differences such as Noe et al (1999); Grann et al (2000); Hershman et al (2002); Melnikow et al (2006), although these studies are carried out under the US health system.

Our findings suggest that introduction of chemoprevention with SERMs targeting extremely high-risk women in Japan can be justifiable as an efficient use of finite health-care resources, possibly contributing to cost containment. The cost saving results suggest chemoprevention not only cost-effective but also affordable. Taking the superiority of raloxifene in outcome gain and the difference in indication into account, it is recommendable to administer tamoxifen for premenopausal women and raloxifene for postmenopausal women.

Our economic model is found sensitive to the utility weight for healthy state under chemoprevention, the discount rate and the cost of chemoprevention, in addition to the probabilities of transition to invasive breast cancer, endometrial cancer, or hip fracture. This is anticipated because these variables are supposed to influence the cost-effectiveness of preventive services. We think that our economic model succeeds in explaining the context under consideration.

\section{REFERENCES}

Armstrong K, Chen TM, Albert D, Randall TC, Schwartz JS (2001) Costeffectiveness of raloxifene and hormone replacement therapy in postmenopausal women: impact of breast cancer risk. Obstet Gynecol 98: $996-1003$

Bevers TB (2007) The STAR trial: evidence for raloxifene as a breast cancer risk reduction agent for postmenopausal women. J Natl Compr Cancer Netw 5: 719-724

Cauley JA, Norton L, Lippman ME, Eckert S, Krueger KA, Purdie DW, Farrerons J, Karasik A, Mellstrom D, Ng KW, Stepan JJ, Powles TJ, Morrow M, Costa A, Silfen SL, Walls EL, Schmitt H, Muchmore DB, Jordan VC, Ste-Marie LG (2001) Continued breast cancer risk reduction
We also analysed the cost-effectiveness of therapeutic policy switch of agent, tamoxifen to raloxifene among postmenopausal women, although this does not depict any marginal change in Japan. All simulated ICERs by risk classifications starting at age 50 and 60 fall in a favourable level. Due caution is needed in transferring these findings from our Japanese model to other health system (Drummond and Pang, 2001), but it implies that the administration of raloxifene instead of tamoxifen for postmenopausal high-risk women could be economically acceptable in developed countries where chemoprevention with tamoxifen is already in practise.

There are a couple of points to consider when interpreting our results. Our model depends on clinical evidence established in the United States by P-1 and P-2 trial. Composition of ethnicity and life styles of participating women are different from those of Japanese women. This also relates to another point, that is the validity of the 5-year risk prediction model defining highrisk women. As already mentioned in Methods section, it is based on Gail et al model 2 (Gail and Costantino, 2001), which has been validated for white women (Rockhill et al, 2001) and African American women (Gail et al, 2007) only. Our approach is acceptable as to these points, as the results of P-1 and P-2 trial are the best available evidence to date for the objectives of this study, and similar risk factors to Gail et al model 2 are identified in a model of individualised probability of developing breast cancer for Japanese women (Ueda et al, 2003), and the function of ethnic difference in developing breast cancer is reported as small (Chen et al, 2004). Our model also depends on utility weights reported from Western countries, as none of those from Japan are available. However, our findings of consistent outcomes in terms of LYGs offer reasonable conclusions.

In summary, this study suggests that chemoprevention of breast cancer with SERMs targeting high-risk women such as a 5-year predicted breast cancer risk of $\geqslant 5.01 \%$, women with a history of LCIS, and women with a history of AH, clears the hurdles of introducing new intervention by means of cost-effectiveness and affordability, with best available evidence. Although further studies and policy formulations are necessary about breast cancer chemoprevention in Japan, this study also implies that the administration of raloxifene instead of tamoxifen may be costeffective under the context of developed countries where chemoprevention with tamoxifen has already been adopted.

\section{ACKNOWLEDGEMENTS}

This study is funded by Japan's Ministry of Health, Labour, and Welfare research grant, a study on the construction of algorithm of multimodality therapy with biomarkers for primary breast cancer by a formulation of the decision-making process, led by Masakazu Toi (H18-3JIGAN-IPPAN-007). We appreciate Mr Hitoshi Mukai and his staff at Tokyo Metropolitan Cancer and Infectious Disease Centre Komagome Hospital for conducting insurance claim reviews. in postmenopausal women treated with raloxifene: 4-year results from the MORE trial. Multiple outcomes of raloxifene evaluation. Breast Cancer Res Treat 65: 125-134

Chau Q, Cantor SB, Caramel E, Hicks M, Kurtin D, Grover T, Elting LS (2003) Cost-effectiveness of the bird's nest filter for preventing pulmonary embolism among patients with malignant brain tumors and deep venous thrombosis of the lower extremities. Support Care Cancer 11: $795-799$

Chen Z, Wu AH, Gauderman WJ, Bernstein L, Ma H, Pike MC, Ursin G (2004) Does mammographic density reflect ethnic differences in breast cancer incidence rates? Am J Epidemiol 159: 140-147 
Cuzick J, Forbes JF, Sestak I, Cawthorn S, Hamed H, Holli K, Howell A, International Breast Cancer Intervention Study I Investigators (2007) Long-term results of tamoxifen prophylaxis for breast cancer - 96-month follow-up of the randomized IBIS-I trial. J Natl Cancer Inst 99: 272 - 282

Cykert S, Phifer N, Hansen C (2004) Tamoxifen for breast cancer prevention: a framework for clinical decisions. Obstet Gynecol 104: $433-442$

de Koning HJ, van Ineveld BM, van Oortmarssen GJ, de Haes JC, Collette HJ, Hendriks JH, van der Maas PJ (1991) Breast cancer screening and cost-effectiveness; policy alternatives, quality of life considerations and the possible impact of uncertain factors. Int J Cancer 49: 531-537

Delmas PD, Bjarnason NH, Mitlak BH, Ravoux AC, Shah AS, Huster WJ, Draper M, Christiansen C (1997) Effects of raloxifene on bone mineral density, serum cholesterol concentrations, and uterine endometrium in postmenopausal women. $N$ Engl J Med 337: 1641-1647

Drummond M, Pang F (2001) Transferability of economic evaluation results. In Economic Evaluation in Health Care: Merging Theory with Practice Drummond $\mathrm{M}$ and McGuire A (eds). Oxford: Oxford University Press

Earle CC, Chapman RH, Baker CS, Bell CM, Stone PW, Sandberg EA, Neumann PJ (2000) Systematic overview of cost-utility assessments in oncology. J Clin Oncol 18: 3302-3317

Eckermann SD, Martin AJ, Stockler MR, Simes RJ (2003) The benefits and costs of tamoxifen for breast cancer prevention. Aust $N Z$ J Public Health 27: $34-40$

Fisher B, Costantino JP, Wickerham DL, Cecchini RS, Cronin WM, Robidoux A, Bevers TB, Kavanah MT, Atkins JN, Margolese RG, Runowicz CD, James JM, Ford LG, Wolmark N (2005) Tamoxifen for the prevention of breast cancer: current status of the National Surgical Adjuvant Breast and Bowel Project P-1 study. J Natl Cancer Inst 97: $1652-1662$

Fuji T, Nakamura M, Yamada N, Kobayashi M, Yamauchi K, Nakano T (2005) Health economic analysis of prevention of deep vein thrombosis an application of pharmacoeconomics. Sogo Rinsho 54: 2988-2997

Fukawa T (1998) Ageing and health expenditure of the elderly. J Jpn Soc Hosp Adm 35: 109-121

Gail MH, Costantino JP (2001) Validating and improving models for projecting the absolute risk of breast cancer. J Natl Cancer Inst 93: 334-335

Gail MH, Costantino JP, Pee D, Bondy M, Newman L, Selvan M, Anderson GL, Malone KE, Marchbanks PA, McCaskill-Stevens W, Norman SA, Simon MS, Spirtas R, Ursin G, Bernstein L (2007) Projecting individualized absolute invasive breast cancer risk in African American women. J Natl Cancer Inst 99(23): 1782-1792

Grann VR, Panageas KS, Whang W, Antman KH, Neugut AI (1998) Decision analysis of prophylactic mastectomy and oophorectomy in BRCA1-positive or BRCA2-positive patients. J Clin Oncol 16: 979-985

Grann VR, Sundararajan V, Jacobson JS, Whang W, Heitjan DF, Antman $\mathrm{KH}$, Neugut AI (2000) Decision analysis of tamoxifen for the prevention of invasive breast cancer. Cancer J 6: 169-178

Hershman D, Sundararajan V, Jacobson JS, Heitjan DF, Neugut AI, Grann VR (2002) Outcomes of tamoxifen chemoprevention for breast cancer in very high-risk women: a cost-effectiveness analysis. J Clin Oncol 20: 9- 16

Hillner BE, Smith TJ, Desch CE (1993) Assessing the cost effectiveness of adjuvant therapies in early breast cancer using a decision analysis model. Breast Cancer Res Treat 25: $97-105$

Iwata H, Saeki T (2006) Current practices in breast cancer treatment in Japan - a questionnaire survey. Jpn J Breast Cancer 21: 311-322

Japan Cancer Society (2007) Gankenshin no jisshi jyokyo. No.39. Tokyo: Japan Cancer Society

Japanese Society of Obstetrics and Gynecology (2000) Zenkoku shikyutaigan chousa seiseki. Dai 5 hou. 1989- 1990 nendo shourei Tokyo: Japanese Society of Obstetrics and Gynecology

Kanis JA, Borgström F, Johnell O, Oden A, Sykes D, Jönsson B (2005) Costeffectiveness of raloxifene in the UK: an economic evaluation based on the MORE study. Osteoporos Int 16: 15-25

Kitamura S, Hasegawa Y, Suzuki S, Sasaki R, Iwata H, Wingstrand H, Thorngren KG (1998) Functional outcome after hip fracture in Japan. Clin Orthop Relat Res 348: 29-36
Martino S, Cauley JA, Barrett-Connor E, Powles TJ, Mershon J, Disch D, Secrest RJ, Cummings SR, CORE Investigators (2004) Continuing outcomes relevant to Evista: breast cancer incidence in postmenopausal osteoporotic women in a randomized trial of raloxifene. J Natl Cancer Inst 96: $1751-1761$

Matsuda S, Ishikawa BK (2003) Kyuuseiki nyuuiniryo shikou shindangunbunrui wo katsuyou shita chousakenkyuu. Report of Health and Labour Sciences Research Grants (Contract No.: H13-SEISAKU-034) Tokyo: Ministry of Health, Labour and Welfare

Melnikow J, Kuenneth C, Helms LJ, Barnato A, Kuppermann M, Birch S, Nuovo J (2006) Chemoprevention: drug pricing and mortality: the case of tamoxifen. Cancer 107: 950 - 958

Ministry of Health, Labour and Welfare (2005a) Vital statistics of Japan. Tokyo: Health \& Welfare Statistics Association

Ministry of Health, Labour and Welfare (2005b) Kokumin iryouhi. Tokyo: Health \& Welfare Statistics Association

Naeim A, Keeler EB (2005) Is adjuvant therapy for older patients with node $(+)$ early breast cancer cost-effective? Breast Cancer Res Treat 94: 95-103

Noe LL, Becker III RV, Gradishar WJ, Gore M, Trotter JP (1999) The cost effectiveness of tamoxifen in the prevention of breast cancer. Am J Manag Care 5: S389-S406

Ohkusa Y (2003) Emprical research for the critical value of expenditure per QALY. Iryo to Shakai 13: 121-130

Powles TJ, Ashley S, Tidy A, Smith IE, Dowsett M (2007) Twenty-year follow-up of the Royal Marsden randomized, double-blinded tamoxifen breast cancer prevention trial. J Natl Cancer Inst 99: 283-290

Rockhill B, Spiegelman D, Byrne C, Hunter DJ, Colditz GA (2001) Validation of the Gail et al model of breast cancer risk prediction and implications for chemoprevention. J Natl Cancer Inst 93(5): $358-366$

Ruof J, Golay A, Berne C, Collin C, Lentz J, Maetzel A (2005) Orlistat in responding obese type 2 diabetic patients: meta-analysis findings and cost-effectiveness as rationales for reimbursement in Sweden and Switzerland. Int J Obes (Lond) 29: 517-523

Sakuma M, Nakamura M, Nakanishi N, Miyahara Y, Tanabe N, Yamada N, Kuriyama T, Kunieda T, Sugimoto T, Nakano T, Shirato K (2004) Inferior vena cava filter is a new additional therapeutic option to reduce mortality from acute pulmonary embolism. Circ J 68: 816-821

Smith TJ, Hillner BE (1993) The efficacy and cost-effectiveness of adjuvant therapy of early breast cancer in premenopausal women. J Clin Oncol 11: $771-776$

Smith TJ, Hillner BE (2000) Tamoxifen should be cost-effective in reducing breast cancer risk in high-risk women. J Clin Oncol 18: 284-286

Trueman P, Drummond M, Hutton J (2001) Developing guidance for budget impact analysis. Pharmacoeconomics 19: 609-621

Ueda K, Tsukuma H, Tanaka H, Ajiki W, Oshima A (2003) Estimation of individualized probabilities of developing breast cancer for Japanese women. Breast Cancer 10: 54-62

Veronesi U, Maisonneuve P, Decensi A (2007a) Tamoxifen: an enduring star. J Natl Cancer Inst 99: 258-260

Veronesi U, Maisonneuve P, Rotmensz N, Bonanni B, Boyle P, Viale G, Costa A, Sacchini V, Travaglini R, D'Aiuto G, Oliviero P, Lovison F, Gucciardo G, del Turco MR, Muraca MG, Pizzichetta MA, Conforti S, Decensi A, Italian Tamoxifen Study Group (2007b) Tamoxifen for the prevention of breast cancer: late results of the Italian Randomized Tamoxifen Prevention Trial among women with hysterectomy. $J$ Nat Cancer Inst 99: 727 - 737

Vogel VG, Costantino JP, Wickerham DL, Cronin WM, Cecchini RS, Atkins JN, Bevers TB, Fehrenbacher L, Pajon Jr ER, Wade III JL, Robidoux A, Margolese RG, James J, Lippman SM, Runowicz CD, Ganz PA, Reis SE, McCaskill-Stevens W, Ford LG, Jordan VC, Wolmark N, National Surgical Adjuvant Breast and Bowel Project (NSABP) (2006) Effects of tamoxifen $v s$ raloxifene on the risk of developing invasive breast cancer and other disease outcomes: the NSABP Study of Tamoxifen and Raloxifene (STAR) P-2 trial. JAMA 295: 2727-2741. Erratum in: JAMA 296:2926, JAMA 298:973 